\title{
Survival prediction tools for esophageal and gastroesophageal junction cancer: A systematic review
}

\author{
Vaibhav Gupta, MD, ${ }^{a}$ Natalie Coburn, MD, MPH, ${ }^{a}$ Biniam Kidane, MD, MSc, ${ }^{b}$ Kenneth R. Hess, PhD, \\ Carolyn Compton, MD, PhD, ${ }^{\mathrm{d}}$ Jolie Ringash, MD, MSc, ${ }^{e}$ Gail Darling, MD, ${ }^{f}$ and Alyson L. Mahar, $\mathrm{PhD}^{\mathrm{g}}$
}

\section{ABSTRACT}

Background: Clinical, pathological, and molecular information combined with cancer stage in prognostication algorithms can offer more personalized estimates of survival, which might guide treatment choices. Our aim was to evaluate the quality of prognostication tools in esophageal cancer.

Methods: We systematically searched MedLine and Embase from 2005 to 2017 for studies reporting development or validation of models predicting long-term survival in esophageal cancer. We evaluated tools using the Critical Appraisal and Data Extraction for Systematic Reviews of Prediction Modelling Studies guidelines and the American Joint Committee on Cancer acceptance criteria for risk models.

Results: We identified 16 prognostication tools for patients treated with curative intent and 1 for patients with metastatic disease. These tools frequently excluded adenocarcinoma, contained outdated data, and were developed with a limited sample size. Nine tools were developed in China for squamous cell cancer, and 11 used data on patients diagnosed before 2010. Most tools excluded key prognostic factors such as age and sex. Tumor stage and grade were the most commonly, but not universally, included factors. Twelve tools were designed to predict overall survival; 5 predicted cancer-specific survival. Bootstrap internal validation was performed for most tools; c-statistics ranged from 0.63 to 0.77 and graphically evaluated calibration was "good." Five tools were externally validated; c-statistics ranged from 0.70 to 0.77 .

Conclusions: Existing tools cannot be confidently used for esophageal cancer prognostication in current clinical practice. Better-quality tools might help to more individually and accurately estimate disease course, select further treatments, and risk-stratify for future clinical trials. (J Thorac Cardiovasc Surg 2018;156:847-56)

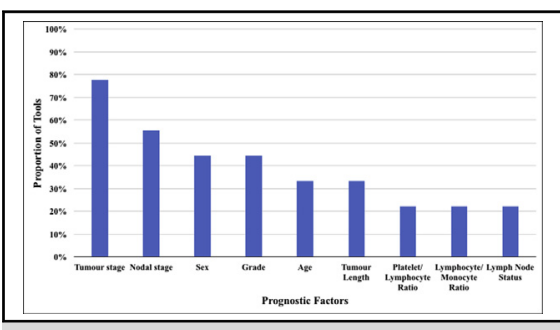

Well recognized prognostic factors are not universally included in prediction tools.

\section{Central Message}

Existing survival prediction tools for esophageal and gastroesophageal junction cancer cannot be confidently used for individualized prognostication in current clinical practice.

\section{Perspective}

Clinical, pathological, and molecular information combined in prognostication algorithms can offer more personalized estimates of survival. Existing tools cannot be confidently used for esophageal cancer prognostication in current clinical practice. Better-quality tools might help to more individually and accurately estimate disease course, select further treatments, and risk-stratify for clinical trials.

See Editorial Commentary page 857.

See Editorial page 845 .

\footnotetext{
From the Divisions of a General Surgery and ${ }^{\mathrm{f}}$ Thoracic Surgery, Department of Surgery, and ${ }^{\mathrm{e}}$ Department of Radiation Oncology, University of Toronto, Toronto, Ontario, Canada; ${ }^{b}$ Section of Thoracic Surgery, Department of Surgery, University of Manitoba, Winnipeg, Manitoba, Canada; ${ }^{\mathrm{C}}$ Department of Biostatistics, The University of Texas M.D. Anderson Cancer Center, Houston, Tex; ${ }^{\mathrm{d}}$ School of Life Sciences, Arizona State University, Tempe, Ariz; and ${ }^{\mathrm{g}}$ Department of Community Health Sciences, University of Manitoba, Winnipeg, Manitoba, Canada.

Received for publication Sept 21, 2017; revisions received Feb 5, 2018; accepted for publication March 3, 2018.

Address for reprints: Alyson L. Mahar, PhD, 4th Floor, Brodie Centre, 727 McDermot Ave, Winnipeg, Manitoba R3E 3P5, Canada (E-mail: alyson_mahar@cpe. umanitoba.ca)

$0022-5223 / \$ 36.00$

Copyright (C) 2018 Published by Elsevier Inc. on behalf of The American Association for Thoracic Surgery

https://doi.org/10.1016/j.jtcvs.2018.03.146
}

Accurate estimates of survival help patients and oncologists improve their ability to make better treatment decisions. This is particularly important in high-fatality cancers such as esophageal cancer (EC), for which the fatality rate approaches $90 \% .^{1-3}$ Incidence of this disease is rapidly increasing in Western countries, ${ }^{3}$ enhancing the relevance of such predictions. Currently, survival in EC is predicted

$\square$ Scanning this QR code will take
you to a supplemental video for
the article.




\section{Abbreviations and Acronyms}

$\begin{aligned} \text { AJCC } & =\text { American Joint Committee on Cancer } \\ \mathrm{EC} & =\text { esophageal cancer } \\ \mathrm{GEJ} & =\text { gastroesophageal junction } \\ \mathrm{TNM}= & \text { Tumor, Node, Metastases } \\ \text { TRIPOD }= & \text { Transparent Reporting of a multivariable } \\ & \text { prediction model for Individual } \\ & \text { Prognosis or Diagnosis }\end{aligned}$

solely on the basis of anatomic stage using the American Joint Committee on Cancer (AJCC) Tumor, Node, Metastases (TNM) staging criteria. However, stage is limited to information about the extent of disease available postoperatively for patients who underwent resection and does not include additional factors that affect survival. Furthermore, heterogeneity in survival is observed even within similarly-staged patients. ${ }^{4}$

Clinical prediction tools combine key prognostic factors to provide more accurate and precise estimates of survival; this can improve outcomes as well as reduce costs by better selecting patients for appropriate treatment. ${ }^{5}$ Patient factors such as age, sex, and comorbidity are associated with survival in many diseases and are increasingly being incorporated into cancer prognostication models to improve accuracy. ${ }^{6-8}$ In esophageal cancer, tumor factors such as histology and treatment response also influence survival. ${ }^{9-11}$ In addition, for patients who undergo surgical resection, pathologic factors associated with survival in the postoperative setting include tumor grade, response to preoperative therapy, number of lymph nodes resected/ positive, resection margins, and the presence of lymphovascular or perineural invasion. ${ }^{12-15}$

In the eighth edition of the TNM staging manual released in 2017, the AJCC formally recognized the importance of using patient and pathological data along with cancer stage to improve prognostication and advocated strongly to improve risk prediction in cancer. ${ }^{16}$ The AJCC has published guidelines for the appraisal of cancer prediction tools. ${ }^{6}$ These guidelines are available in the form of a checklist with 13 inclusion and 3 exclusion criteria that readers can apply in evaluating a prediction tool to ensure its quality and applicability to practice. To summarize, they ensure that tools: predict survival outcomes, have clinical relevance, include important predictors, specify the target population, test validation to ensure generalizability, clearly define when the prediction is calculated, assess and meet certain statistical standards, and report appropriate details such that the model can be implemented by the user.

Using these guidelines, the AJCC has reviewed the quality of tools across a number of cancer sites, $7,8,17,18$ and endorsed tools that have met this standard for colorectal, lung, melanoma, breast, and prostate cancer. ${ }^{19}$ It is unclear whether or not gaps exist in the EC prognostic tool literature or any recommendations for which tools should be used in practice. Therefore, the objective of this study was to systematically review the literature for studies reporting development or validation of models predicting survival in EC.

\section{METHODS}

\section{Search Strategy and Selection Criteria}

Our review was inclusive of tools predicting long-term (not perioperative) survival for esophageal and gastroesophageal junction (GEJ) cancer, adenocarcinoma, or squamous cell carcinoma, curativeintent or metastatic patients, and designed for use either pre- or postoperatively. Prognostication tools were identified using 2 strategies: (1) a search of the peer-reviewed published literature (a systematic literature review and cited reference search); and (2) a Google Web-based search.

The search strategy was executed in OVID MedLine and OVID Embase from Jan 1, 2005 to April 19, 2017. Medical subject headings did not exist for prognostication tools and so a combination of alternate headings and key words identified in consultation with a scientific librarian for a previous review were used. ${ }^{7}$ Each set of search terms was modified for the specific search engine. The following search terms were used in MedLine: "models, statistical/," "prognosis," "predict* model*," "nomogram/," "prognos* model*," "esophageal neoplasms/," "esophageal squamous cell carcinoma/," "adenocarcinoma of the esophagus/," and "esophagogastric junction." The searches were limited to English language. Seemingly eligible studies were excluded if they met any of the following a priori exclusion criteria: (1) assessment of the prognostic effect of a single factor (unless it was updating the accuracy of an existing prognostic tool), (2) inappropriate analytic purpose (eg, multivariate modeling not aimed at prognostication, development of novel statistical methods), (3) not limited only to EC patients, (4) not original data/research (eg, editorial, review), or (5) the outcome was not longterm survival. Studies reporting on perioperative mortality (eg, predicting 30-day mortality after esophagectomy) were not the focus of this review and were excluded.

Prognostication tools in this report include those developed to estimate the probability of survival at a particular point along the disease trajectory (eg, at diagnosis, after treatment) or for the purpose of using a survival probability to inform treatment decision-making. Eligible survival end points included any time-to-death analyses (eg, overall survival, cause-specific survival, relative survival), as well as vital status analyses (eg, probability of death at 5 years after diagnosis). Generally speaking, some form of statistical model underlies most prognostication tools, and we use the terms prognostication tool and prognostication model interchangeably. Two reviewers (V.G., A.L.M.) assessed the titles and abstracts of citations for inclusion. Percent agreement was 95\%. Differences were resolved through a discussion of discordant decisions. A cited reference search using Web of Science was performed to decrease the probability of missing a relevant article. These peer-reviewed literature search strategies to identify prognostic tools in EC were supplemented by a Google Web-based search. Search terms included: "clinical prediction tool," "online calculator," or "nomogram," combined with "esophageal cancer," "esophagogastric cancer," or "gastroesophageal cancer.",

\section{Data Abstraction}

A detailed report on data abstraction form development and key definitions was published previously. ${ }^{7,20}$ The data abstracted allowed an evaluation of tool development and validation methodology and clinical 
relevance. The final criteria include all key elements described by the Transparent Reporting of a multivariable prediction model for Individual Prognosis Or Diagnosis (TRIPOD) guidelines and the Critical Appraisal and Data Extraction for Systematic Reviews of Prediction Modelling Studies checklist. ${ }^{20}$ General descriptive information such as study design, study population characteristics, prognostic factors considered, and outcome measurement were abstracted, as were specific details on tool development (statistical modeling decisions, candidate variable selection), and validation (internal and external validation methods, measures of model predictive accuracy).

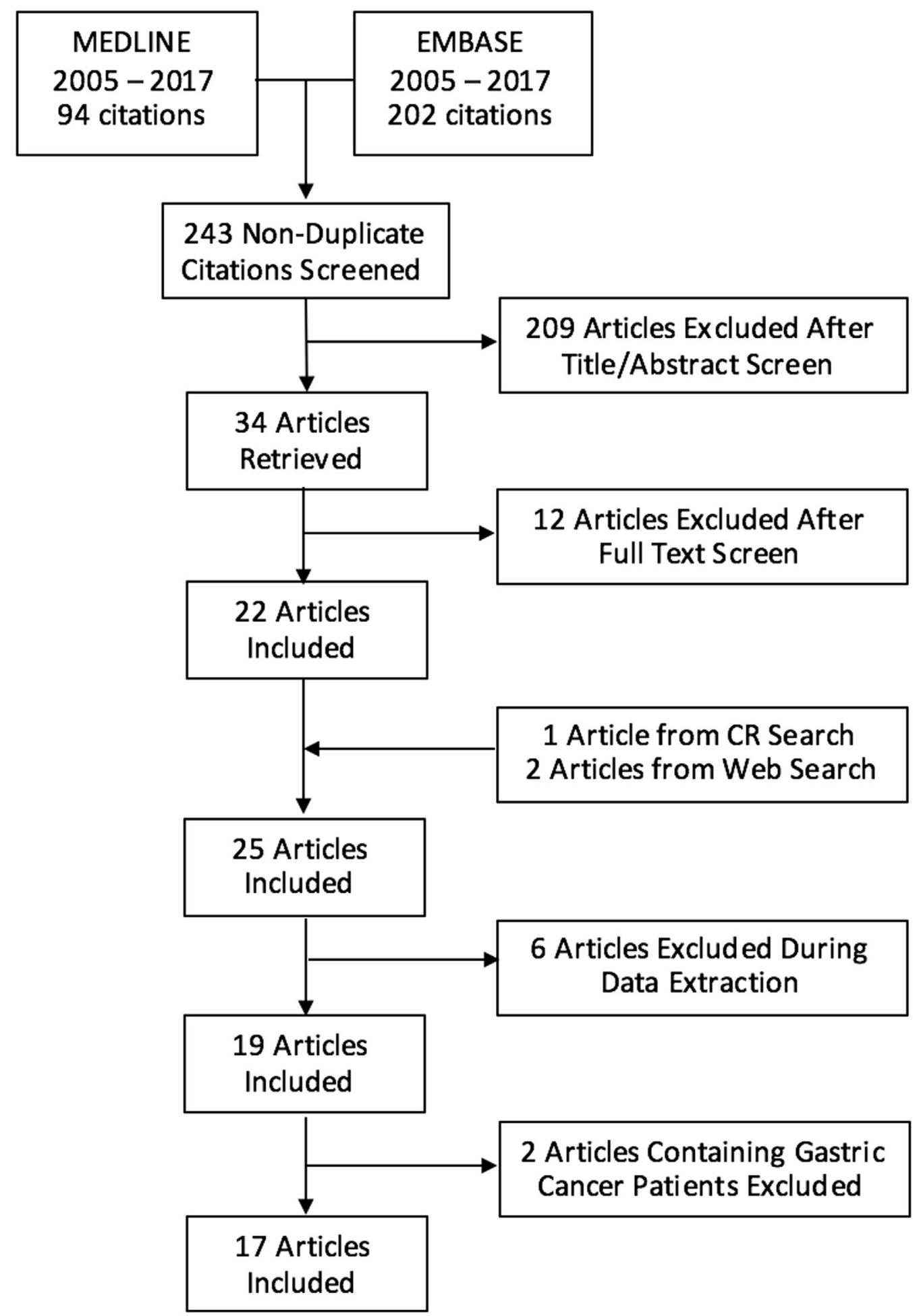

FIGURE 1. Results of the search for clinical prognostic tools and their validation articles on esophageal cancer. $C R$, Cited reference. 


\begin{tabular}{|c|c|c|c|c|c|c|c|c|c|c|c|c|c|}
\hline $\begin{array}{c}\text { Tool/ } \\
\text { reference }\end{array}$ & Data source & Population & $\begin{array}{c}\text { Data } \\
\text { collection }\end{array}$ & $\begin{array}{l}\text { Exclude } \\
\text { nCRT? }\end{array}$ & $\begin{array}{l}\text { Study } \\
\text { design }\end{array}$ & $\begin{array}{l}\text { Sample } \\
\text { size }\end{array}$ & $\begin{array}{l}\text { Follow-up } \\
\text { time }\end{array}$ & Outcome & $\begin{array}{c}\text { Outcome } \\
\text { anchor } \\
\text { (time } \\
\text { zero) }\end{array}$ & $\begin{array}{l}\text { Number } \\
\text { of events* }\end{array}$ & Variables & $\begin{array}{c}\text { Internal } \\
\text { validation } \\
\text { C-statistic } †\end{array}$ & $\begin{array}{c}\text { External } \\
\text { validation } \\
\text { C-statistic }\end{array}$ \\
\hline \multicolumn{14}{|l|}{$\begin{array}{r}\text { Resected AC } \\
\text { and SCC }\end{array}$} \\
\hline Cao et $\mathrm{al}^{23}$ & USA & Esophagus & 1988 to 2007 & NR & $\mathrm{R}$ & 4109 & Med. $28 \mathrm{mo}$ & CSS & Dx date & NR & $\begin{array}{l}\text { Age, race, histology, tumor site, } \\
\text { tumor size, grade, T stage, } \\
\mathrm{N} \text { stage, number of LNs } \\
\text { harvested }\end{array}$ & $\begin{array}{c}0.72(0.71- \\
0.73)\end{array}$ & $\begin{array}{c}0.70(0.64- \\
0.76)\end{array}$ \\
\hline Eil et $\mathrm{al}^{29}$ & USA & $\begin{array}{l}\text { Esophagus, } \\
>65 \mathrm{y}\end{array}$ & 1997 to 2005 & No & $\mathrm{R}$ & 824 & NR & OS & NR & NR & $\begin{array}{l}\text { Age, sex, histology, T stage, } \\
\text { N stage, number of LNs } \\
\text { harvested, CRT }\end{array}$ & 0.72 & None \\
\hline Shapiro et $\mathrm{al}^{35}$ & $\begin{array}{l}\text { The } \\
\text { Netherlands }\end{array}$ & Esophagus & 2001 to 2013 & No & $\mathrm{P}$ & 626 & NR & OS & OR date & NR & $\begin{array}{l}\text { Clinical N stage, pathological } \\
\mathrm{T} \text { and } \mathrm{N} \text { stage }\end{array}$ & 0.63 & None \\
\hline \multicolumn{14}{|l|}{ Resected AC } \\
\hline $\begin{array}{l}\text { Gabriel } \\
\text { et }^{3 l^{30}}\end{array}$ & USA & Esophagus & 2006 to 2012 & No & $\mathrm{R}$ & 6129 & Med. $48.8 \mathrm{mo}$ & OS & NR & 3491 & $\begin{array}{l}\text { Age, } \mathrm{T} \text { stage, } \mathrm{N} \text { stage, grade, } \\
\text { comorbidity, nCRT }\end{array}$ & 0.68 & None \\
\hline Zhou et $\mathrm{al}^{43}$ & USA & GEJ & 2004 to 2011 & NR & $\mathrm{R}$ & 953 & Avg. $25.5 \mathrm{mo}$ & OS & NR & NR & $\begin{array}{l}\text { Age, sex, depth of invasion, } \\
\text { number of LNs positive, } \\
\text { number of LNs harvested, } \\
\text { grade }\end{array}$ & $\begin{array}{c}0.69(0.66- \\
0.72)\end{array}$ & $\begin{array}{c}0.75(0.71- \\
0.79)\end{array}$ \\
\hline Lagarde et al ${ }^{32,44}$ & $\begin{array}{l}\text { The } \\
\text { Netherlands }\end{array}$ & Esophagus & 1993 to 2003 & Yes & $P$ & 364 & Min. $20 \mathrm{mo}$ & CSS & CSS & 228 & $\begin{array}{l}\text { T stage, } \mathrm{LN} \text { ratio, } \\
\text { extracapsular LNI }\end{array}$ & $\begin{array}{c}0.77(0.74- \\
0.80)\end{array}$ & 0.76 \\
\hline \multicolumn{14}{|l|}{ Resected SCC } \\
\hline Su et $\mathrm{al}^{37}$ & China & Esophagus & 2000 to 2009 & Yes & $\mathrm{R}$ & 797 & Min. $18 \mathrm{mo}$ & OS & OR date & NR & $\begin{array}{l}\text { Tumor size, surgical approach, } \\
\text { number of LNs harvested/ } \\
\text { positive, grade, depth } \\
\text { of invasion }\end{array}$ & $\begin{array}{c}0.73(0.69- \\
0.76)\end{array}$ & $\begin{array}{c}0.72(0.67- \\
0.76)\end{array}$ \\
\hline Shao et $\mathrm{al}^{34}$ & China & Esophagus & 2002 to 2012 & Yes & $\mathrm{R}$ & 916 & Med. $39 \mathrm{mo}$ & OS & OR date & NR & $\begin{array}{l}\text { Grade, T stage, } \mathrm{N} \text { stage, } \\
\text { CRP/Alb ratio, NLR }\end{array}$ & $\begin{array}{c}0.77(0.74- \\
0.81)\end{array}$ & $\begin{array}{c}0.76(0.71- \\
0.82)\end{array}$ \\
\hline Wang et $\mathrm{al}^{40}$ & China & Esophagus & 2006 to 2008 & NR & $\mathrm{R}$ & 205 & Med. 48 mo & OS & OR date & 153 & $\begin{array}{l}\text { T stage, LN status, TNM stage, } \\
\text { grade, vascular invasion, } \\
\text { UBEC } 2 \text { C expression, } \\
\text { MGP expression }\end{array}$ & NR & None \\
\hline Chen et $\mathrm{al}^{25}$ & China & Esophagus & 2005 to 2008 & Yes & $\mathrm{R}$ & 308 & NR & CSS & Dx date & NR & $\begin{array}{l}\text { Age, sex, } T \text { stage, } N \text { stage, } \\
\text { M stage, PLR, CRP/PNI ratio }\end{array}$ & 0.69 & None \\
\hline Yu et $\mathrm{al}^{42}$ & China & Esophagus & 2004 to 2011 & Yes & $\mathrm{R}$ & 1004 & Med. $67.5 \mathrm{mo}$ & OS & OR date & NR & $\begin{array}{l}\text { Adjuvant treatment, grade, } \\
\text { tumor embolus, LN ratio, } \\
\text { T stage, tumor site }\end{array}$ & $\begin{array}{c}0.70(0.67- \\
0.73)\end{array}$ & None \\
\hline Chen et $\mathrm{al}^{24}$ & China & Esophagus & 2006 to 2008 & Yes & $\mathrm{R}$ & 277 & Med. 42.6 mo & CSS & OR date & NR & Age, sex, T stage, $\mathrm{N}$ stage, RDW & 0.68 & None \\
\hline Liu et $\mathrm{al}^{33}$ & China & Esophagus & 2006 to 2008 & Yes & $\mathrm{R}$ & 326 & Med. 45 mo & CSS & OR date & NR & T stage, $\mathrm{N}$ stage, PLR, LMR, GPS & 0.72 & None \\
\hline Duan et $\mathrm{al}^{28}$ & China & Esophagus & 2006 to 2010 & Yes & $\mathrm{R}$ & 328 & Med. 44.9 mo & OS & OR date & NR & $\begin{array}{l}\text { Sex, tumor size, } \\
\text { T stage, } \mathrm{N} \text { stage, } \mathrm{CT}\end{array}$ & $\begin{array}{c}0.71(0.63- \\
0.79)\end{array}$ & $\begin{array}{c}0.77(0.60- \\
0.93)\end{array}$ \\
\hline
\end{tabular}




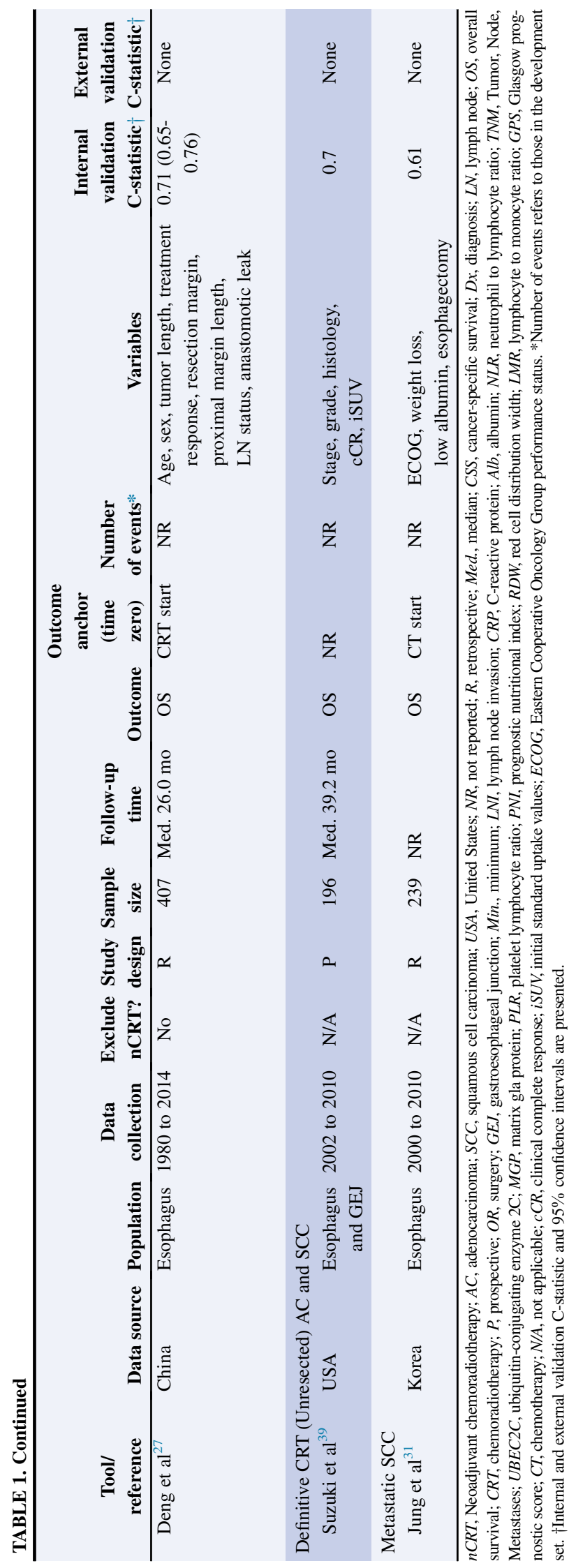

\section{Summary}

Descriptive statistics related to tool development and validations are reported in summary tables. The assessment of a tool's discrimination and/or calibration was defined as a formal statistical evaluation of the internal or external validity. Model discrimination assesses the ability of the model to distinguish between high- and low-risk patients. Model calibration assesses how closely the predicted values of the outcome match the observed outcomes in the study sample. These established methods are considered the best means of evaluating a clinical prediction model..$^{5,21,22}$ We did not describe when tools were assessed informally through a comparison of survival time distributions across prognostic groups (Kaplan-Meier survival curves). Although these are the same statistical methods that are often used to evaluate the prognostic ability of TNM stage, they are not considered statistically robust, nor best practice for assessment of clinical prediction tool predictive performance. ${ }^{5,22}$

\section{Evaluation of Tool Quality}

The Precision Medicine Core of the AJCC has developed and published criteria to evaluate the quality of prognostication tool development and whether they can be recommended for use in clinical practice. ${ }^{6}$ We evaluated all tools against these criteria.

\section{RESULTS}

\section{Literature Search Results}

Figure 1 shows the search results. The scientific literature review, cited reference, and Web-based search identified 19 prognostication tools $\mathrm{s}^{23-43}$ and 1 article that contained an external validation only. ${ }^{44}$ No articles were published to update previously developed tools with additional prognostic information. We did not identify any articles that evaluated the effectiveness or implementation of tools in clinical practice. One article evaluated the net benefit of using the tool in clinical practice using decision curve analyses. ${ }^{34}$

Overall, 15 tools were developed for EC, 1 for GEJ cancers, 1 for esophageal as well as GEJ cancers, and 2 for gastroesophageal cancers. The 2 gastroesophageal cancer tools included stomach cancer patients, and were excluded. ${ }^{26,36}$ In the remainder of this article we discusses the 17 esophagus and GEJ cancer tools.

Thirteen tools ( $76 \%$ ) provided a visual nomogram, 1 tool was available as a Web-based calculator, 2 tools were presented as risk scores or risk groupings, and 1 tool was provided as an equation only. Four tools provided the statistical equation, including coefficients and the intercept for a particular time point of prediction (when appropriate). The TRIPOD guidelines recommend this information is published along with the clinical operationalization of the prediction tool to allow adequate external validation with appropriate statistical methods. ${ }^{5}$

\section{Tool Development Methods}

Table 1 describes key information abstracted from each study. Further supporting aggregate information is reported.

None of the included studies were prospectively designed to collect data with the purpose of creating a clinical prediction tool. Three studies used data that were 
prospectively collected in a clinical database to understand prognosis and disease recurrence, but not with the goal of creating a prediction tool. Most tools (56\%) used data from patients diagnosed and treated in China or the United States $(29 \%)$. Most tools $(65 \%)$ were developed using data collected from patients diagnosed or treated in 2010 or earlier. The median prediction tool development cohort sample size was 407, ranging from 196 to 6129 patients. Twelve tools $(71 \%)$ were designed to predict overall survival; 5 predicted cancerspecific survival. Four articles $(24 \%)$ did not report the amount of follow-up and $14(82 \%)$ did not report the number of deaths occurring during the study period. The median amount of follow-up ranged from 26 to 67.5 months and the number of reported deaths ranged from 153 to 3491 .

Table 2 summarizes tool development methodology information. Almost all tools (14 of 17) identified prognostic factors for inclusion through some $P$ value-based variable selection method. In addition, 3 tools selected prognostic variables opportunistically according to the availability of data in existing databases. Most tools did not report how missing data on variables were handled, whereas 2 indicated using an imputation-based approach, as recommended in TRIPOD. ${ }^{5}$ Most tools $(76 \%)$ dichotomized or categorized continuous prognostic factors (eg, age). Categorization of continuous data is not recommended by the TRIPOD guidelines, but is often cited as necessary to ease practical application of a clinical prediction tool. ${ }^{5}$ All but 3 studies used Cox proportional hazards regression models to develop their prognostication tool. Four tools did not provide an anchor point (the event that marks time 0) to measure survival; of those that did, most (9 of 13) were designed to predict survival from the date of surgery, 1 from the start of chemoradiotherapy, 1 from the start of chemotherapy, and 2 from the date of diagnosis. Very few (2 of 17) studies reported verifying the statistical assumptions of the underlying mathematical models.

\section{Populations and Prognostic Factors}

Table 1 shows the populations addressed by each prognostication tool. Most tools (10 of 17) were developed to address prognostication in patients with squamous cell carcinoma. Most prognostication tools targeted patients with EC undergoing surgical resection (15 of 17); of those, only 4 tools included patients also receiving neoadjuvant chemoradiotherapy (trimodality therapy), which is the current standard of care as curative-intent treatment. ${ }^{10}$

There was significant heterogeneity in the prognostic factors included in tools. For example, in the 9 tools designed to prognosticate for patients with squamous-cell esophageal tumors undergoing surgical resection, the median number of prognostic factors included in each tool was 6 (range, 5-8), and 31 factors were included in total. None of the prognostic factors were common to all 9 tools. Most of the factors (22 of 31) were included exclusively in a single tool (Table 3). $\mathrm{T}$ and $\mathrm{N}$ stage were the most commonly included, present in 7 and 5 tools each (Figure 2).

\section{Internal Validity}

Table 4 shows a summary of assessment of each tool's predictive performance. All but 1 of the studies assessed the internal validity. ${ }^{40}$ More than half of the studies (11 of 16) assessed model performance using bootstrapping, which decreases the likelihood of overestimating model performance, and is an approach recommended by TRIPOD. ${ }^{5}$ Model calibration was assessed graphically for 9 tools, and typically "good" calibration was interpreted by the authors without a corresponding evaluation of model fit statistics, subgroup comparisons, the line of identity, or calibration slopes. All studies that assessed internal validity reported a concordance index, which might vary from 0.5 (model predictions are similar to chance) to 1.0 (model predictions are perfect). Model discrimination ranged from 0.63 to 0.77 . When studies using bootstrapping techniques only were evaluated, the concordance index range did not change.

\section{External Validity}

More than half of the tools (11 of 17) did not have an evaluation of model performance in a group of similar patients seen at a different institution or during a different time period (external validation). Five prognostication tools each had a single evaluation; none of the external validations were performed by researchers independent of those involved in tool development. The external validation cohort sample size ranged from 76 to 382 patients (median, 181). Only 1 study reported the number of events in the validation cohort. ${ }^{32}$ Concordance indices reported across external validations ranged from 0.70 to 0.77 . Most studies reported wide $95 \%$ confidence limits, as the result of their small sample sizes.

\section{TOOL QUALITY}

Of the 17 tools identified, only 2 did not trigger either of the 2 exclusion criteria set by the AJCC. Most were excluded because of the lack of reporting on the extent and effect of missing data. Table 5 shows the assessment of the remaining 2 tools against the AJCC criteria., ${ }^{6,30,32}$ The tool developed by Gabriel et al to assess the benefit of neoadjuvant chemoradiotherapy could meet all criteria for use, if the authors provided the point of time that prognostication for their patient population began (eg, survival from the time of surgery, diagnosis) and the number of deaths in the development cohort. ${ }^{30}$

\section{DISCUSSION}

We systematically reviewed the literature on clinical prediction tools for long-term survival in EC (Video 1). We found 16 tools for patients treated with curative intent and 1 tool for patients with metastatic disease. Discrimination 
TABLE 2. Methodological criteria evaluated for clinical prognostication tools for patients with esophageal cancer $(n=17)$

\begin{tabular}{lc}
\hline \multicolumn{1}{c}{ Methodological criterion } & $\mathbf{n}(\%)$ \\
\hline Prognostic factor selection method & \\
$\quad$ Literature-based/clinical reasoning & $2(12)$ \\
$\quad \begin{array}{l}\text { Screened using univariable/multivariable selection } \\
\quad \text { methods }\end{array}$ & $14(82)$ \\
$\quad$ Method not specified & $1(6)$ \\
Methods for handling missing data & \\
Complete case analysis & $2(12)$ \\
Imputation & $2(12)$ \\
Method not specified & $13(76)$ \\
Description of handling continuous predictors* & \\
Linear & $2(12)$ \\
Cubic spline & $3(18)$ \\
Transformed & $1(6)$ \\
Dichotomized/categorized & $13(76)$ \\
Method not specified & $2(12)$ \\
Analytic model used & \\
Cox proportional hazards regression & $14(82)$ \\
Log-Logistic regression & $1(6)$ \\
Cluster analysis & $1(6)$ \\
Method not specified & $1(6)$ \\
Statistical model assumptions checked & $2(12)$ \\
\hline
\end{tabular}

*Studies may have used multiple methods if they had multiple continuous variables, so that percentages do not add up to 100. Dichotomization/categorization is not the recommended method of handling continuous predictors.

was weak or moderate and calibration was good (observed survival frequently approximated predicted survival) for all models. Most of the tools did not meet the minimum set of criteria developed by the AJCC to identify high-quality, clinically useful prognostication tools. The tool developed by Gabriel and colleagues met almost all of the published AJCC criteria for a well developed and clinically relevant tool. ${ }^{6,30}$ It is built from a cohort of 6129 patients identified in the National Cancer Database who underwent neoadjuvant chemoradiotherapy and surgery for esophageal adenocarcinoma between 2006 and 2012. They included important prognostic variables, applied appropriate statistical methods, and showed good predictive performance. The Gabriel tool is an ideal candidate for external validation provided the outcome anchor and number of deaths in the cohort are clarified. The extent of available, well developed tools relative to the number of novel tools published in the past 5 years represents an important gap in current care, and the development and validation of robust tools in clinically important scenarios would be an important step toward realizing personalized care in EC.

In many regards, the quality of prognostication tool reporting for EC is superior to other reviewed cancer sites. ${ }^{7,8,17,18}$ All tools identified had a corresponding, peer-reviewed publication describing the development and technical details. Most studies reported an appropriate
TABLE 3. List of prognostic factors common to only 1 of the 9 tools predicting survival for patients with resected squamous cell esophageal cancer

\begin{tabular}{l}
\hline Number of adjuvant chemotherapy cycles \\
Number of LNs positive \\
Number of LNs examined \\
Adjuvant treatment \\
Anastomotic leak \\
CRP/Alb ratio \\
\hline CRP/PNI ratio \\
\hline Depth of invasion \\
\hline Tumor embolus \\
Extent of positive LNs \\
\hline Glasgow prognostic score \\
MGP expression \\
\hline Neutrophil/lymphocyte ratio \\
Proximal margin length \\
\hline Red cell distribution width \\
Resection margin \\
\hline Surgical approach \\
\hline TNM stage \\
\hline Treatment response \\
\hline Tumor site \\
\hline UBEC2C expression \\
\hline Vascular invasion \\
\hline$L N$, Lymph node; $C R P$, C-reactive protein; $A l b$, albumin; $P N I$, prognostic nutritional \\
index; $M G P$, matrix gla protein; $T N M$, Tumor, Node, Metastases; $U B E C 2 C$, \\
ubiquitin-conjugating enzyme $2 \mathrm{C}$.
\end{tabular}

outcome anchor, described their variable selection strategy and handling of continuous variables, and internally validated the model with bootstrapping. In addition, these studies appropriately used standard discrimination and calibration statistics to assess model performance, whereas in other cancer sites, tool performance is often only evaluated by comparing survival curves between different prognostic groups.

Despite these strengths, however, shortcomings were documented with regard to development, reporting, and current clinical relevance of prognostic tools in EC. Most tools used data from the 1980s to the early 2000s, with few cohorts including patients treated in the current decade. This is important because the landmark studies that guide treatment today were published between 2005 and 2015, ${ }^{10}$ and thus tools on the basis of earlier data reflect treatment with outdated protocols. Neoadjuvant (preoperative) chemoradiation is the current standard of care for locally advanced EC, however, only 4 studies specifically included patients who underwent this treatment protocol. ${ }^{27,30,35,45}$ Furthermore, data from the 1990s and early 2000s do not reflect the results of modern chemotherapy, radiotherapy, and surgical care. External 


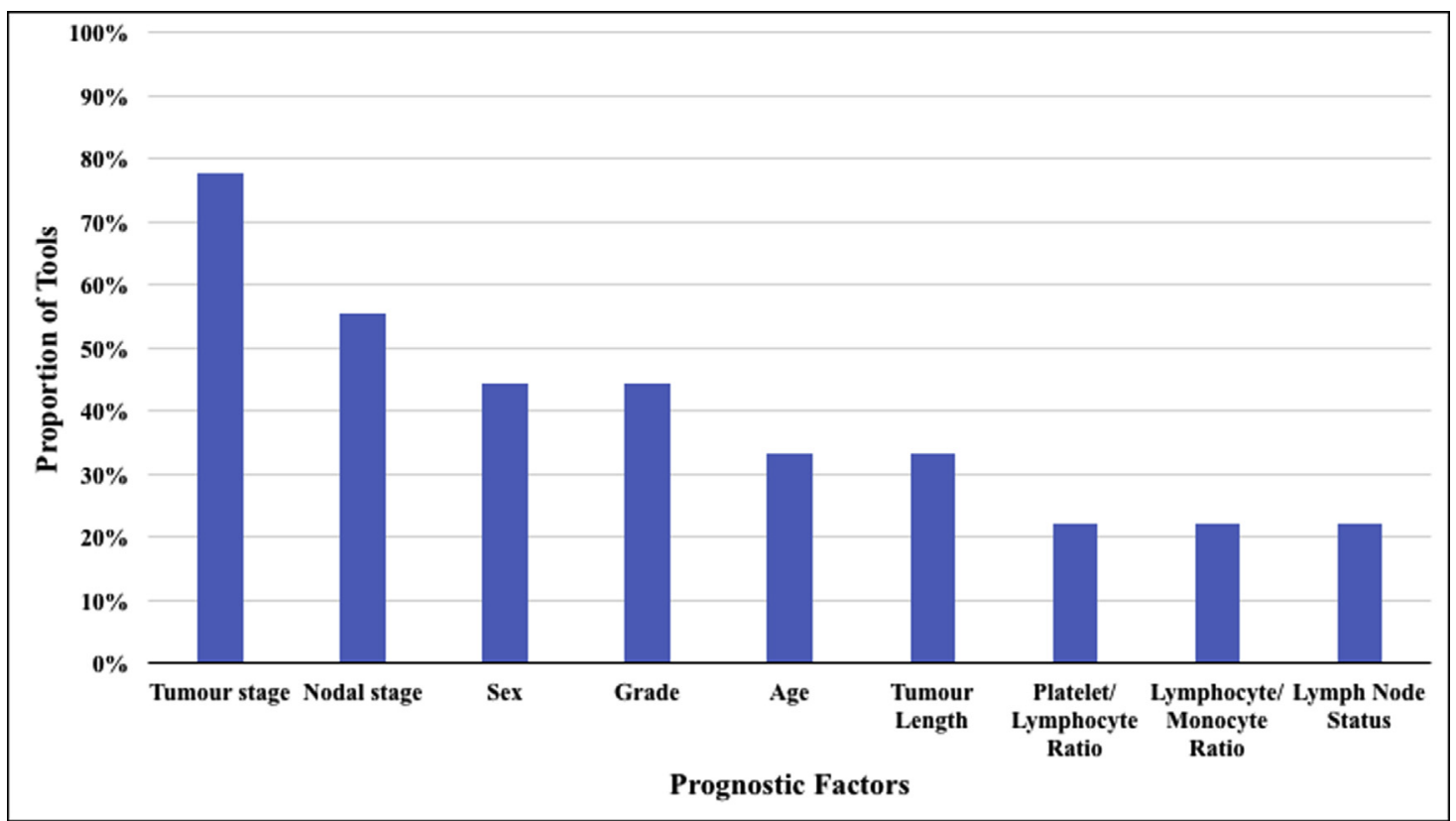

FIGURE 2. The number of prognostic factors common to more than 1 tool predicting survival for patients with resected squamous cell esophageal cancer $(\mathrm{n}=9)$.

validation and recalibration of these tools in modern cohorts could help address these issues, but has not been completed for most tools, thus significantly limiting their applicability to practice today.

Similar to other reviews of oncology prognostication tools, significant variation was documented in the number and types of prognostic factors included in the identified tools. Variation in variable inclusion might be driven by the use of statistical rules, rather than clinical knowledge, to select predictors in the model, the secondary use of data from sources or studies not designed to develop a

TABLE 4. Details of evaluations of tool internal and external validity $(\mathrm{n}=\mathbf{1 7}$ tools $)$

\begin{tabular}{lcc}
\hline Performance measure & $\begin{array}{c}\text { Internal } \\
\text { validation } \\
(\mathbf{n}=\mathbf{1 6} \text { tools })\end{array}$ & $\begin{array}{c}\text { External } \\
\text { validation } \\
(\mathbf{n}=\mathbf{6} \text { validations })\end{array}$ \\
\hline $\begin{array}{l}\text { Internal validation method } \\
\text { Apparent }\end{array}$ & $5(31)$ & - \\
$\quad$ Bootstrapping & $11(69)$ & - \\
External validation method & - & $0(0)$ \\
$\quad$ Independent & - & $4(67)$ \\
$\quad \begin{array}{l}\text { Geographic } \\
\text { Temporal }\end{array}$ & - & $2(33)$ \\
Calibration & & \\
$\quad \begin{array}{l}\text { Graph (plot/intercept/slope) } \\
\text { Other* }\end{array}$ & $9(56)$ & $4(67)$ \\
Discrimination & $1(6)$ & $1(17)$ \\
C-statistic $\dagger$ & $16(100)$ & $5(83)$ \\
\hline
\end{tabular}

*Plotted observed and expected survival in a Kaplan-Meier curve. †Concordance index on the basis of the receiver operating characteristic area under the curve for binary data, Harrell C statistic for models using time to event data. prognostication tool at the time point of interest, or because the study was designed to evaluate the prognostic ability of biomarkers not routinely used in practice. Well established prognostic factors such as cancer stage, age, and sex were missing from many tools, limiting their utility in the real world. Data-driven selection strategies are likely to overestimate predictive ability because they optimize case mix and statistical relationships specific to the development data set (overfitting); models developed in this way are less likely to perform well in other populations. The ideal tool would incorporate clinically relevant factors $a$ priori in the model to improve face validity and facilitate tool adoption in the community.

The lack of information on missing data on prognostic variables, number of deaths, and follow-up time were significant issues in prognostic tool development reporting and create barriers to clinical use. Because many tools were developed and published before the circulation and widespread dissemination of the TRIPOD guidelines across the medical community, these limitations might be easily addressed in future research at the time of study design. Better reporting and understanding of the effect of missing data could mean more reliable and accurate predictions. Authors of existing tools might benefit from reaching out to organizations such as the AJCC to bridge the current gap between model development and implementation, thereby facilitating effective knowledge translation.

During this review we identified 3 articles that evaluated gene signatures to study their relationship to survival; these tools did not consider any existing, known predictors but rather explored the significance of new genes in 
TABLE 5. Quality assessment of tools that did not trigger the AJCC exclusion criteria

\begin{tabular}{cccc}
\hline \multicolumn{1}{c}{ Citation } & Population & Inclusion criteria met, n & AJCC recommended \\
\hline Gabriel et al $^{30}$ & $\begin{array}{c}\text { Esophageal adenocarcinoma patients undergoing resection and } \\
\text { nCRT }\end{array}$ & 13 of 14 & Tentative yes \\
Lagarde et al $^{32,44}$ & Esophageal adenocarcinoma patients undergoing resection & 10 of 14 & No \\
\hline
\end{tabular}

AJCC, American Joint Commission on Cancer; $n C R T$, neoadjuvant chemoradiotherapy.

isolation. ${ }^{38,46,47}$ Genomic analysis might be important in the future as DNA/RNA sequencing becomes widely available for clinical application, but genomic data alone do not currently constitute a useful basis for prognostication in individual patients. $^{48}$

There are some limitations to note in this systematic review, specifically our definition of prognosis and literature search parameters. We focused on the prognostication of long-term survival and did not include studies predicting perioperative mortality. Warnell and colleagues specifically reviewed this literature in 2015 and concluded these studies suffered some of the same limitations we described, including poor discrimination, unreliable performance, and poorly-managed biases. ${ }^{49}$ We also limited our search to English-language studies and might not have captured tools developed or implemented in some parts of the world. This might especially be true because of the large proportion of tools published outside of North America and Europe. We mitigated this by performing a Web-based search for all tools regardless of a corresponding publication. This review also followed TRIPOD, Critical Appraisal and Data Extraction for Systematic Reviews of Prediction Modelling Studies Checklist, and AJCC guidelines to

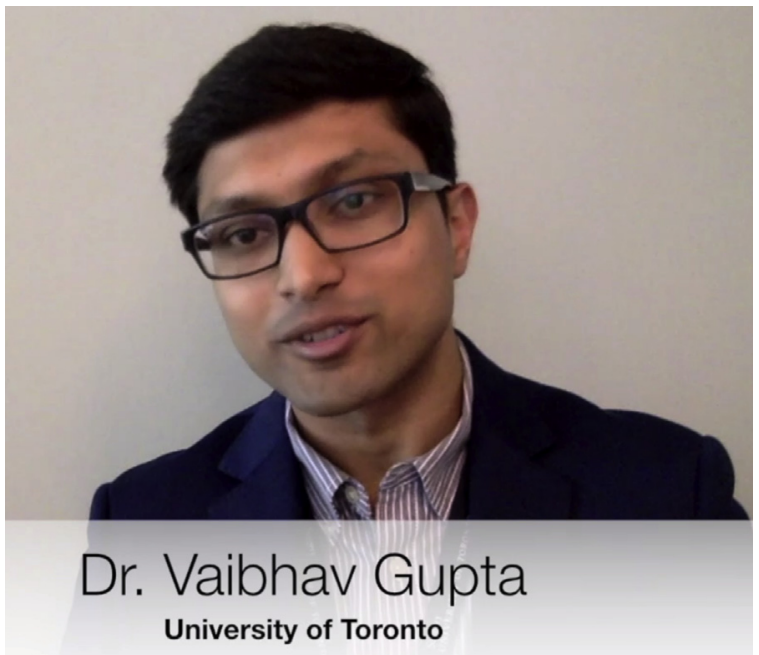

VIDEO 1. Dr Vaibhav Gupta explains the importance and relevance of the study. Video available at: https://www.jtcvs.org/article/S0022-5223(18) 30937-1/fulltext. identify and critically appraise studies, which limits the potential for bias in our conclusions.

Prediction tools in cancer care can help achieve more personalized, patient-centered care. In addition to cancer stage, considering an individual's age, sex, comorbidities, treatment received, response to therapy, and specific surgical pathology (where available) can make survival predictions more accurate and patient-centered. With the exception of the tool developed by Gabriel et al, none of the tools identified in our review are ideal for use in current clinical practice. ${ }^{30}$ This tool might be suitable for clinical application when the outcome anchor for prognostication and number of deaths is described, it is externally validated, and potentially recalibrated in a population-based data set. The availability and acceptability of a well developed and validated tool might help to more individually and accurately estimate disease course, select further treatments, and risk-stratify for future clinical trials.

\section{Conflict of Interest Statement}

Authors have nothing to disclose with regard to commercial support.

\section{References}

1. Canadian Cancer Society's Advisory Committee on Cancer Statistics. Canadian Cancer Statistics 2017. Toronto, Canada: Canadian Cancer Society; 2017.

2. Cancer Research UK. Oesophageal cancer survival statistics, England and Wales, 2010-2011. Available at: http://www.cancerresearchuk.org/health-professional/ cancer-statistics/statistics-by-cancer-type/oesophageal-cancer/survival. Accessed July 19, 2017

3. Botterweck AA, Schouten LJ, Volovics A, Dorant E, van Den Brandt PA. Trends in incidence of adenocarcinoma of the oesophagus and gastric cardia in ten European countries. Int J Epidemiol. 2000;29:645-54.

4. Rice TW, Chen LQ, Hofstetter WL, Smithers BM, Rusch VW, Wijnhoven BP, et al. Worldwide Esophageal Cancer Collaboration: pathologic staging data. Dis Esophagus. 2016;29:724-33.

5. Moons KG, Altman DG, Reitsma JB, Ioannidis JP, Macaskill P, Steyerberg EW, et al. Transparent Reporting of a multivariable prediction model for individual prognosis or diagnosis (TRIPOD): explanation and elaboration. Ann Intern Med. 2015;162:W1-73

6. Kattan MW, Hess KR, Amin MB, Lu Y, Moons KG, Gershenwald JE, et al. American Joint Committee on cancer acceptance criteria for inclusion of risk models for individualized prognosis in the practice of precision medicine. $C A$ Cancer J Clin. 2016;66:370-4.

7. Mahar AL, Compton C, McShane LM, Halabi S, Asamura H, Rami-Porta R, et al Refining prognosis in lung cancer: a report on the quality and relevance of clinical prognostic tools. J Thorac Oncol. 2015;10:1576-89.

8. Mahar AL, Compton C, Halabi S, Hess KR, Gershenwald JE, Scolyer RA, et al. Critical assessment of clinical prognostic tools in melanoma. Ann Surg Oncol. 2016;23:2753-61.

9. Siewert JR, Stein HJ, Feith M, Bruecher BL, Bartels H, Fink U. Histologic tumor type is an independent prognostic parameter in esophageal cancer: lessons from more than 1,000 consecutive resections at a single center in the western world Ann Surg. 2001;234:360-7; discussion: 368-9. 
10. Jang R, Darling G, Wong RK. Multimodality approaches for the curative treatment of esophageal cancer. J Natl Compr Canc Netw. 2015;13:229-38.

11. Ajani JA, D'Amico TA, Almhanna K, Bentrem DJ, Besh S, Chao J, et al. Esophageal and esophagogastric junction cancers, version 1.2015. J Natl Compr Canc Netw. 2015;13:194-227.

12. Berger AC, Farma J, Scott WJ, Freedman G, Weiner L, Cheng JD, et al. Complete response to neoadjuvant chemoradiotherapy in esophageal carcinoma is associated with significantly improved survival. J Clin Oncol. 2005;23:4330-7.

13. Javidfar J, Speicher PJ, Hartwig MG, D'Amico TA, Berry MF. Impact of positive margins on survival in patients undergoing esophagogastrectomy for esophageal cancer. Ann Thorac Surg. 2016;101:1060-7.

14. Chan DS, Reid TD, Howell I, Lewis WG. Systematic review and meta-analysis of the influence of circumferential resection margin involvement on survival in patients with operable oesophageal cancer. Br J Surg. 2013;100:456-64.

15. Rizk NP, Ishwaran H, Rice TW, Chen LQ, Schipper PH, Kesler KA, et al. Optimum lymphadenectomy for esophageal cancer. Ann Surg. 2010;251:46-50.

16. Rice TW, Kelsen DP, Blackstone EH, Ishwaran H, Patil DT, Bass AJ, et al. Esophagus and esophagogastric junction. In: Amin MB, Edge SB, Greene FL, eds. AJCC Cancer Staging Manual. 8th ed. New York, NY: Springer; 2017: $185-202$.

17. Mahar AL, Jiang L, Webber C, Groome PA. A Review of Prognostic Tools in Breast and Prostate Cancer: For the American Joint Committee on Cancer. Kingston, ON: Queen's Univeristy; 2014.

18. Mahar AL, Compton C, Halabi S, Hess KR, Weiser MR, Groome PA. Personalizing prognosis in colorectal cancer: a systematic review of the quality and nature of clinical prognostic tools for survival outcomes. J Surg Oncol. 2017;116: 969-82.

19. American Joint Committee on Cancer. AJCC Cancer Staging Manual. 8th ed. New York: Springer International Publishing; 2017.

20. Moons KG, de Groot JA, Bouwmeester W, Vergouwe Y, Mallett S, Altman DG, et al. Critical appraisal and data extraction for systematic reviews of prediction modelling studies: the CHARMS checklist. PLoS Med. 2014;11:e1001744.

21. Steyerberg EW. Clinical Prediction Models: A Practical Approach to Development, Validation, and Updating. New York, NY: Springer New York; 2009.

22. Collins GS, Reitsma JB, Altman DG, Moons KG. Transparent reporting of a multivariable prediction model for individual prognosis or diagnosis (TRIPOD): the TRIPOD statement. BMJ. 2015;350:g7594.

23. Cao J, Yuan P, Wang L, Wang Y, Ma H, Yuan X, et al. Clinical nomogram for predicting survival of esophageal cancer patients after esophagectomy. Sci Rep. 2016;6:26684.

24. Chen GP, Huang Y, Yang X, Feng JF. A nomogram to predict prognostic value of red cell distribution width in patients with esophageal cancer. Mediators Inflamm. 2015;2015:854670.

25. Chen S, Yang X, Feng JF. A novel inflammation-based prognostic score for patients with esophageal squamous cell carcinoma: the c-reactive protein/prognostic nutritional index ratio. Oncotarget. 2016;7:62123-32.

26. Custodio A, Carmona-Bayonas A, Jimenez-Fonseca P, Sanchez ML, Viudez A, Hernandez R, et al. Nomogram-based prediction of survival in patients with advanced oesophagogastric adenocarcinoma receiving first-line chemotherapy: a multicenter prospective study in the era of trastuzumab. Br J Cancer. 2017; 116:1526-35.

27. Deng W, Wang Q, Xiao Z, Tan L, Yang Z, Zhou Z, et al. A prognostic nomogram for overall survival after neoadjuvant radiotherapy or chemoradiotherapy in thoracic esophageal squamous cell carcinoma: a retrospective analysis. Oncotarget. 2017;8:41102-12.

28. Duan J, Deng T, Ying G, Huang D, Zhang H, Zhou L, et al. Prognostic nomogram for previously untreated patients with esophageal squamous cell carcinoma after esophagectomy followed by adjuvant chemotherapy. Jpn J Clin Oncol. 2016;46: 336-43.

29. Eil R, Diggs BS, Wang SJ, Dolan JP, Hunter JG, Thomas CR. Nomogram for predicting the benefit of neoadjuvant chemoradiotherapy for patients with esophageal cancer: a SEER-Medicare analysis. Cancer. 2014;120:492-8.

30. Gabriel E, Attwood K, Shah R, Nurkin S, Hochwald S, Kukar M. Novel calculator to estimate overall survival benefit from neoadjuvant chemoradiation in patients with esophageal adenocarcinoma. J Am Coll Surg. 2017;224: 884-94.e1.
31. Jung HA, Adenis A, Lee J, Park SH, Maeng CH, Park S, et al. Nomogram to pre dict treatment outcome of fluoropyrimidine/platinum-based chemotherapy in metastatic esophageal squamous cell carcinoma. Cancer Res Treat. 2013;45: 285-94.

32. Lagarde SM, Reitsma JB, de Castro SM, Ten Kate FJ, Busch OR, van Lanschot JJ. Prognostic nomogram for patients undergoing oesophagectomy for adenocarcinoma of the oesophagus or gastro-oesophageal junction. $\mathrm{Br} \mathrm{J}$ Surg. 2007;94:1361-8.

33. Liu JS, Huang Y, Yang X, Feng JF. A nomogram to predict prognostic values of various inflammatory biomarkers in patients with esophageal squamous cell carcinoma. Am J Cancer Res. 2015;5:2180-9.

34. Shao Y, Ning Z, Chen J, Geng Y, Gu W, Huang J, et al. Prognostic nomogram integrated systemic inflammation score for patients with esophageal squamous cell carcinoma undergoing radical esophagectomy. Sci Rep. 2015;5:18811.

35. Shapiro J, van Klaveren D, Lagarde SM, Toxopeus EL, van der Gaast A, Hulshof MC, et al. Prediction of survival in patients with oesophageal or junctional cancer receiving neoadjuvant chemoradiotherapy and surgery. Br J Surg. 2016;103:1039-47.

36. Shiozaki H, Slack RS, Chen HC, Elimova E, Planjery V, Charalampakis N, et al. Metastatic gastroesophageal adenocarcinoma patients treated with systemic therapy followed by consolidative local therapy: a nomogram associated with longterm survivors. Oncology. 2016;91:55-60.

37. Su D, Zhou X, Chen Q, Jiang Y, Yang X, Zheng W, et al. Prognostic nomogram for thoracic esophageal squamous cell carcinoma after radical esophagectomy. PLoS One. 2015;10:e124437.

38. Sun LL, Wu JY, Wu ZY, Shen JH, Xu XE, Chen B, et al. A three-gene signature and clinical outcome in esophageal squamous cell carcinoma. Int J Cancer. 2015; 136:E569-77.

39. Suzuki A, Xiao L, Hayashi Y, Blum MA, Welsh JW, Lin SH, et al. Nomograms for prognostication of outcome in patients with esophageal and gastroesophageal carcinoma undergoing definitive chemoradiotherapy. Oncology. 2012;82:108-13.

40. Wang W, Wang Z, Zhao J, Wei M, Zhu X, He Q, et al. A novel molecular and clinical staging model to predict survival for patients with esophageal squamous cell carcinoma. Oncotarget. 2016;7:63526-36.

41. Wu J, Chen QX. Prognostic and predictive significance of tumor length in patients with esophageal squamous cell carcinoma undergoing radical resection. BMC Cancer. 2016;16:394.

42. Yu S, Zhang W, Ni W, Xiao Z, Wang X, Zhou Z, et al. Nomogram and recursive partitioning analysis to predict overall survival in patients with stage IIB-III thoracic esophageal squamous cell carcinoma after esophagectomy. Oncotarget. 2016;7:55211-21.

43. Zhou Z, Zhang H, Xu Z, Li W, Dang C, Song Y. Nomogram predicted survival of patients with adenocarcinoma of esophagogastric junction. World J Surg Oncol. 2015;13:197.

44. Lagarde SM, Reitsma JB, Ten Kate FJ, Busch OR, Obertop H, Zwinderman AH, et al. Predicting individual survival after potentially curative esophagectomy for adenocarcinoma of the esophagus or gastroesophageal junction. Ann Surg. 2008; 248:1006-13.

45. Eil RL, Thomas CR Jr. New methodology, tools, and protocolized analysis are needed to advance individualized treatment paradigms in esophageal cancer. Dis Esophagus. 2014;27:360-1.

46. Cao HH, Zheng CP, Wang SH, Wu JY, Shen JH, Xu XE, et al. A molecular prognostic model predicts esophageal squamous cell carcinoma prognosis. PLoS One. 2014;9:e106007.

47. Cao HH, Zhang SY, Shen JH, Wu ZY, Wu JY, Wang SH, et al. A three-protein signature and clinical outcome in esophageal squamous cell carcinoma. Oncotarget. $2015 ; 6: 5435-48$.

48. Michiels S, Ternes N, Rotolo F. Statistical controversies in clinical research: prognostic gene signatures are not (yet) useful in clinical practice. Ann Oncol. 2016;27:2160-7.

49. Warnell I, Chincholkar M, Eccles M. Predicting perioperative mortality after oesophagectomy: a systematic review of performance and methods of multivariate models. Br J Anaesth. 2015;114:32-43.

Key Words: prediction model, nomogram, survival, esophageal cancer, personalized medicine 